\title{
What Do Young Athletes Implicitly Understand About Psychological Skills?
}

\author{
Paul J. McCarthy \\ Glasgow Caledonian University \\ Marc V. Jones \\ Staffordshire University \\ Chris G. Harwood \\ Loughborough University \\ Steve Olivier \\ University of Abertay
}

\begin{abstract}
One reason sport psychologists teach psychological skills is to enhance performance in sport; but the value of psychological skills for young athletes is questionable because of the qualitative and quantitative differences between children and adults in their understanding of abstract concepts such as mental skills. To teach these skills effectively to young athletes, sport psychologists need to appreciate what young athletes implicitly understand about such skills because maturational (e.g., cognitive, social) and environmental (e.g., coaches) factors can influence the progressive development of children and youth. In the present qualitative study, we explored young athletes' (aged 10-15 years) understanding of four basic psychological skills: goal setting, mental imagery, self-talk, and relaxation. Young athletes ( $n=118: 75$ males and 43 females) completed an open-ended questionnaire to report their understanding of these four basic psychological skills. Compared with the older youth athletes, the younger youth athletes were less able to explain the meaning of each psychological skill. Goal setting and mental imagery were better understood than self-talk and relaxation. Based on these findings, sport psychologists should consider adapting interventions and psychoeducational programs to match young athletes' age and developmental level.
\end{abstract}

Psychological skills comprise learned behaviors used by athletes and if practiced prudently, have been theorized to serve them in their pursuit of sporting excellence (Kremer \& Moran, 2008; Murphy \& Tammen, 1998). These skills include various constructs such as motivation, self-confidence, arousal control, and interpersonal

Paul J. McCarthy is with the Department of Psychology at Glasgow Caledonian University in Glasgow, UK. Marc V. Jones is with the Centre for Sport and Exercise Research at Staffordshire University in Staffordshire, UK. Chris Harwood is with the School of Sport and Exercise Sciences at Loughborough University in Leicestershire, UK. Steve Olivier is with the School of Health and Social Services at the University of Abertay in Dundee, Scotland, UK. 
skills that are central to sport psychology practice (Anderson, Miles, Mahoney, \& Robinson, 2002; Corlett, 1996; Thomas, 1990). Although many elite athletes bear testament to the value of psychological skills for enhancing practice and competition, sport psychologists are not fully aware of their effectiveness with young athletes because cognitive developmental processes associated with learning and using psychological skills are rarely discussed in the sport psychology literature. Even less literature guides the professional practice of sport psychologists working with young athletes. Given these limitations, and acknowledging that psychological skills such as goal setting, self-talk, mental imagery, and relaxation have been the "workhorses in the applied sport psychology canon" (Andersen, 2000, p. ix), it is important to appreciate what young athletes understand about psychological skills to teach these skills effectively. The goal of this study, therefore, is to identify what young athletes implicitly understand about these four psychological skills using an open-ended questionnaire.

Young athletes encounter physical, social, psychological, and emotional changes as they mature in sport, challenging the sport psychologist to understand and respond appropriately to the stages of change in their development (Wiese-Bjornstal, LaVoi, \& Omli, 2009). Although our awareness of these changes has a strong research base in developmental psychology, these changes are barely acknowledged in pediatric sport psychology. In response to this oversight, sport psychologists are now beginning to include developmental frameworks to understand how athletes progress in sport (Harwood \& Knight, 2009; McCarthy \& Jones, 2007; McCarthy, Jones, \& Clark-Carter, 2008; Weiss \& Weiss, 2006). Along this line, two distinct bodies of research have emerged: (a) career transitions and (b) talent identification (Bruner, Erickson, McFadden, \& Côté, 2009). Career transition literature offers a perspective on the athlete's career, including both psychosocial variables that affect development during critical transitions and a developmental perspective on athlete transitions. This developmental perspective is welcomed because sport researchers have traditionally neglected changes in cognitive structures, thus limiting the understanding of maturational differences in psychological processes and behaviors (Scanlan, Babkes, \& Scanlan, 2005; Weiss \& Bredemeier, 1983).

Cognitive structures shape psychological processes and social and emotional behavior throughout childhood and adolescence, especially during the transition between late childhood and early adolescence when young athletes often decide whether to commit to or withdraw from sport. The talent development literature labels these stages the sampling (ages 7-12 years) and specializing years (age 13-16 years). During the sampling years, children develop basic identities, motives, values, and beliefs about sport that are critical for maintaining long-term sport involvement. When children enter the specializing years, they begin to specialize in one or two sports, often choosing one activity over another because of critical incidents such as positive experiences with a coach, encouragement from an older sibling, success, and/or simple enjoyment of the activity (Côté, Baker, \& Abernethy, 2007). In slight contrast, the career transitions literature offers a life-span development model (Wylleman, Alfermann, \& Lavallee, 2004) using four concurrent levels: athletic, psychological, psychosocial, and academic/vocational. At the athletic level, athletes can pass through four possible stages that are tentatively linked to approximate ages: (a) the initiation stage (6-7 years), during which the young athlete is introduced to organized sport; (b) the development stage (12-13 years), when the athlete's talent is 
recognized and more intense training and participation in competitions is warranted; (c) the mastery stage (18-19 years), when the athlete begins participating at the highest competitive level; and (d) the discontinuation stage, which reflects the elite athlete's transition out of competitive sport (28-35 years). The psychological level comprises three stages based on different conceptual frameworks for psychological development, such as Erikson's (1963) psychosocial stages of development, Piaget's (1963) stages of cognitive development, and Havighurst's (1973) developmental tasks over the lifespan. These stages are childhood, adolescence, and adulthood. The third level represents the psychosocial development of athletes, anchored in their athletic involvement. An athlete receives various social contributions from others during an athletic career. For example, parents play a key role in socializing their child into sport; however, as the child gets older, although parents are still involved, peers play a more significant role in psychosocial development (Horn \& Weiss, 1991; Wiese-Bjornstal et al., 2009). Finally, the fourth level represents the academic/vocational transitions into primary education, secondary education, higher education, and vocational training or a professional occupation of the athlete. Overall, this framework comprehensively accounts for the athletic, psychological, psychosocial, and academic/vocational elements of the young athlete's life.

Although sport psychologists work with athletes across the lifespan (Corlett, 1996), professional practice research typically focuses on adult athletes. Yet, with many young athletes competing in professional sports, and organizations investing in centers of excellence for youth sport around the world (e.g., tennis, golf, soccer, rugby), young athletes now represent a growing client base for the sport psychologist. To fulfill goals of accountability (Smith, 1989) and effectiveness (Partington \& Orlick, 1987), sport psychologists should place greater focus on addressing the needs of young athletes, especially as adult expectations for young athletes emerge independent of their cognitive, social, emotional, and psychomotor developmental levels. These expectations and other stressors such as harsh coaches, injury, performance setbacks, and losses place challenges on young athletes that require effective coping (Wiese-Bjornstal et al., 2009). As such, athletes (and all humans) typically cope using three coping methods: problem-focused, emotion-focused, or avoidance (Billings \& Moos, 1984; Lazarus \& Folkman, 1984). Problem-focused coping involves attempting to change the situation; emotion-focused coping involves managing emotions associated with the situation; and avoidance coping involves removing oneself from the situation. Sport psychologists often deliver individualized psychological skills training involving cognitive- and somatic-based strategies for controlling stress and dealing with adversity. These self-regulatory psychological skills could promote enjoyable and competent sport performance (Wiese-Bjornstal et al., 2009). Yet, sport psychology researchers have largely neglected to study self-regulatory psychological skills for young athletes. This is particularly disappointing, because over 20 years ago, Vealey (1988) suggested that because children are developing physically and psychologically, they may benefit more from psychological skills training than older athletes who have already internalized dysfunctional responses to competition. In professional practice, the sport psychologist can acknowledge the cognitive, emotional, social, and physical development of young athletes and foster developmental assets (e.g., commitment to learning, self-esteem, social support) using selected psychological skills to maximize the experience of sport (Benson, 1997; Fraser-Thomas, Côté, \& Deakin, 2005; Harwood, 2008). The challenge 
remains, however, to adapt and teach psychological skills to young athletes so that they will successfully assimilate and integrate them into practice and competition (Harwood, Cumming, \& Fletcher, 2004; Harwood, Cumming, \& Hall, 2003; Lane, Harwood, Terry, \& Karageorghis, 2004). Yet if sport psychologists are unaware of the nuances of child development, then the effectiveness of such interventions may potentially be reduced (Stallard, 2002, 2005). Although sport psychology service is complex, some would suggest that when sport psychologists abide by the cardinal rule to "follow the client" (Andersen, 2009), the client will be well served. If the four primary psychological skills of goal setting, mental imagery, self-talk, and relaxation, which form the basis of much research and practical application in sport psychology, are to be appropriate for the young client, then the extent to which young athletes understand and value them should be recognized to enhance the effectiveness of psychological skills training.

\section{Method}

\section{Participants}

Young athletes ( $n=118 ; 75$ males and 43 females) between 10 and 15 years of age (Mage $=13.25, S D=1.24)$ participated in this study. The athletes had participated in school or organized sport, competing at county and regional levels in England. Participants were in the sampling $(n=22)$ and specializing $(n=96)$ years of sport participation. Participants were recruited from primary $(n=1)$ and secondary schools $(n=2)$ randomly selected from the Department of Education and Skills list of all primary and secondary schools in the locality. Participants were involved in a range of sports including soccer, cricket, basketball, netball, cycling, snooker, table tennis, and track and field.

\section{Measures}

Open-Ended Questionnaire. Participants completed an open-ended questionnaire to explore what young athletes implicitly understand about the terms goal setting, mental imagery, self-talk, and relaxation in the context of sport. These basic psychological skills (Andersen, 2000; Hardy, Jones, \& Gould, 1996) can be used alone or as subcomponents of a multimodal intervention. We adopted this qualitative approach because it helped determine not only what young athletes understand about psychological skills, but also the processes through which their understanding develops over time (Davis \& Meyer, 2009).

\section{Procedure}

The university research committee provided initial permission to conduct this study. After approval, head teachers from three primary and three secondary schools received a letter detailing the nature of the survey. One primary and two secondary schools agreed to participate in the study. Next, parental consent was sought. A week before data collection, parents received letters explaining the nature of the study and their right to withdraw their child at any time. Children signed assent forms before completing the questionnaire. The first author administered surveys 
in a classroom setting during school hours with a class teacher present; he also explained the nature of the survey and encouraged participants to ask questions if they did not understand the task.

Participants completed an open-ended questionnaire comprising four questions specifically designed for this study. On the open-ended questionnaire, participants wrote answers to the following questions about the four basic psychological skills: "What do you think goal setting means?" "What do you think mental imagery means?" "What do you think self-talk means?" and "What do you think relaxation means?" with the generic stem: "I think this means. .." Participants were asked to leave the space blank if they did not understand the meaning of the term.

\section{Data Analysis}

The open-ended questionnaires were transcribed and the content was analyzed using the procedures recommended for inductive content analysis (Miles \& Huberman, 1994; Patton, 2002). The first author organized raw data into interpretable and meaningful themes and categories that emerged from the transcriptions. Using hierarchical induction, first- and second-order themes emerged through clustering raw data around underlying uniformities. This process continued until general dimensions emerged; at which point, it was impossible to create a new level of themes. The second and third authors validated the procedure at each stage to maintain procedural consistency. Through critical questioning by the second and third authors, consensus on the main themes emerged. In an effort to establish trustworthiness within this qualitative research process (Biddle, Markland, Gilbourne, Chatzisarantis, \& Sparkes, 2001; Hardy et al., 1996), the third author, trained in qualitative research, served as a "devil's advocate" (Marshall \& Rossman, 1995), questioning the methods, procedures, and content analyses used in the process. Extensive procedural detail documented the credibility and transferability of the research.

Although grounded theory is claimed to be inductive, Glaser and Strauss (1967) acknowledged that researchers cannot enter the research process without biases. As such, researchers can affect the research process to some extent by combining the raw data with their own beliefs (Eccles, Walsh, \& Ingledew, 2002), providing a constructionist revision of grounded theory at an epistemological level (Pidgeon \& Henwood, 1997). Therefore, we used the following operational definitions of the four basic psychological skills to serve as a guide to categorize the participants' responses and to maintain procedural consistency among the authors. Operational definitions also help to integrate concepts into higher order theory (Eccles et al., 2002). The psychological skills were defined as follows: Goal setting is the process by which people establish desirable objectives for their performance and achievements (Moran, 1996); mental imagery is using all the senses to recreate or create an experience in the mind (Vealey \& Greenleaf, 2006); self-talk is a multidimensional phenomenon focusing on athletes' self-verbalizations, which can serve both instructional and motivational functions (Hardy, Hall, \& Hardy, 2005); and relaxation is a technique used to reduce arousal (Hardy et al., 1996). Participants were categorized into three groups: low-, moderate-, or high-level respondents. These groups represent participants' knowledge and understanding of the four basic psychological skills, collectively. Low-level respondents $(n=35)$ did not respond accurately to any, or at most responded accurately to only one, open- 
ended question. Moderate-level respondents $(n=23)$ responded accurately to two or three open-ended questions. Finally, high-level respondents $(n=60)$ responded accurately to all four open-ended questions.

\section{Results}

\section{Descriptive Analysis}

An assessment of the average chronological age of each group of respondents indicated a possible developmental difference in responses between the three groups; however, we did not explicitly measure cognitive development. Specifically, lowand moderate-level respondents had a mean age of 12.77 years $(S D=1.5)$ and 12.78 years $(S D=1.57)$, respectively, whereas the high-level respondents had a mean age of 13.7 years $(S D=.36)$. A one-way ANOVA established that a statistically significant age difference emerged among the low-, moderate-, and high-level respondents, $\left.F(2,116)=8.17, p=0.001, \eta^{2}=0.15\right)$. Post hoc comparisons using the Tukey HSD test indicated that the mean age of high-level respondents $(M=$ 13.7) was significantly different from moderate-level $(M=12.78)$ and low-level respondents $(M=12.77)$. On closer inspection, the lower end of the age range (10-11 year olds) was mainly within the low- $(n=12)$ and moderate-response $(n$ $=8$ ) categories, with only two respondents in the high-response category. Variation in responses for each psychological skill within each category emerged. In the low-level response category $(n=35)$, responses that were consistent with the guiding definitions outlined in the design of this study were provided for goal setting $(n=9)$ and imagery $(n=3)$ only. Relaxation and self-talk did not receive appropriate responses. The moderate-level response group $(n=23)$ provided the most appropriate responses for goal setting $(n=21)$, followed by imagery $(n=$ $20)$, relaxation $(n=14)$, and self-talk $(n=4)$. The high-level response group $(n=$ 60) provided detailed responses for each question that were consistent with the guiding definitions outlined in the design of this study. In short, this screening process demonstrated that participants in the sampling and specializing stages of sport participation have a modest knowledge and understanding of these basic psychological skills. With increasing chronological age, however, better explanations of psychological skills emerged. This finding draws attention to a possible cognitive-developmental association with abstract concepts that sport psychologists can address when working with young athletes, especially those who have not reached the formal operational stage (approximately 12 years of age) of cognitive development (Piaget, 1963, 1970).

\section{Content Analysis}

Research findings are presented in sequence, with higher-order themes described initially, followed by relevant lower-order themes (see Figures 1-4).

Goal Setting. In general, the respondents (i.e., those providing a response) reported that goal setting was "a target or challenge to achieve" and it related to "personal improvement." Ninety participants' (76\%) completed responses were recorded (see Figure 1). The higher-order theme of "target to achieve" accounted for $48 \%$ of the total responses. The respondents indicated that goal setting was 
$1^{\text {st }}$ order themes $\quad 2^{\text {nd }}$ order themes General dimension

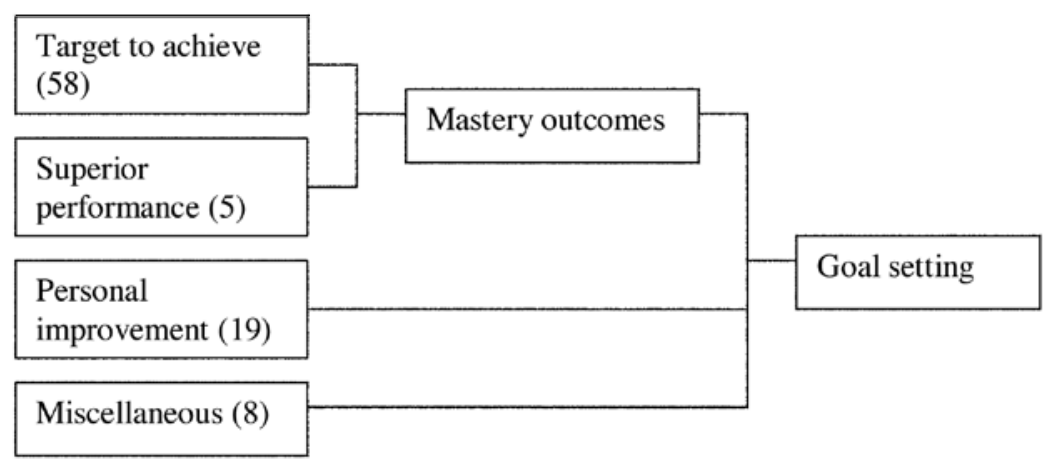

Figure 1 - Hierarchical structure of general dimension: goal setting.

"setting yourself a target to achieve," "to get as high as possible and achieve your dreams," and "set yourself personal targets to achieve." A goal is that which an individual is trying to accomplish and in most goal-setting studies, goal setting refers to attaining a specific level of proficiency in a task (Weinberg, 2002). The following themes provide specific examples of attaining a level of proficiency. Specifically, "superior performance" accounted for $4 \%$ of the total responses and consisted of raw data themes such as "trying to win a match" and "where to come in a race and who to beat." "Personal improvement" accounted for $8 \%$ of the total responses. This theme related to the use of goal setting to improve performance. Examples include, "set goals for yourself to make you play better," "set goals to aim higher," and finally, "if you don't reach it (your target), it makes you try a bit harder." The respondents provided most examples of outcome and performance goals, with a limited number of process goals, though further probing may have elicited process goals. In summary, using the definition of goal setting (Moran, 1996) as a guide, $63 \%$ the respondents indicated a general understanding of the concept of goal setting.

Mental Imagery. In addition to the guiding definition of mental imagery by Vealey and Greenleaf (2006), the raw data were categorized using Hall and colleagues' (Hall, Mack, Paivio, \& Hausenblas, 1998; Martin, Moritz, \& Hall, 1999) five specific functions of mental imagery: motivation general-mastery (MG-M), motivation general-arousal (MG-A), motivation-specific (MS), cognitive-general (CG), and cognitive-specific (CS). Of these five categories, only three categories emerged from the raw data: motivation-specific (e.g., imagining winning a medal), motivation general-mastery (e.g., imagining appearing confident in front of others), and cognitive-general (e.g., imagining various strategies for a competitive event). Eighty-three participants' (70\%) completed responses were recorded (see Figure 2).

Fifteen percent of the total participants identified mental imagery as motivationspecific, such as, "seeing yourself winning" and "I see myself winning the match." Nineteen percent of the participants reported mental imagery as motivation general- 

$1^{\text {st }}$ order theme
$2^{\text {nd }}$ order theme
General dimension

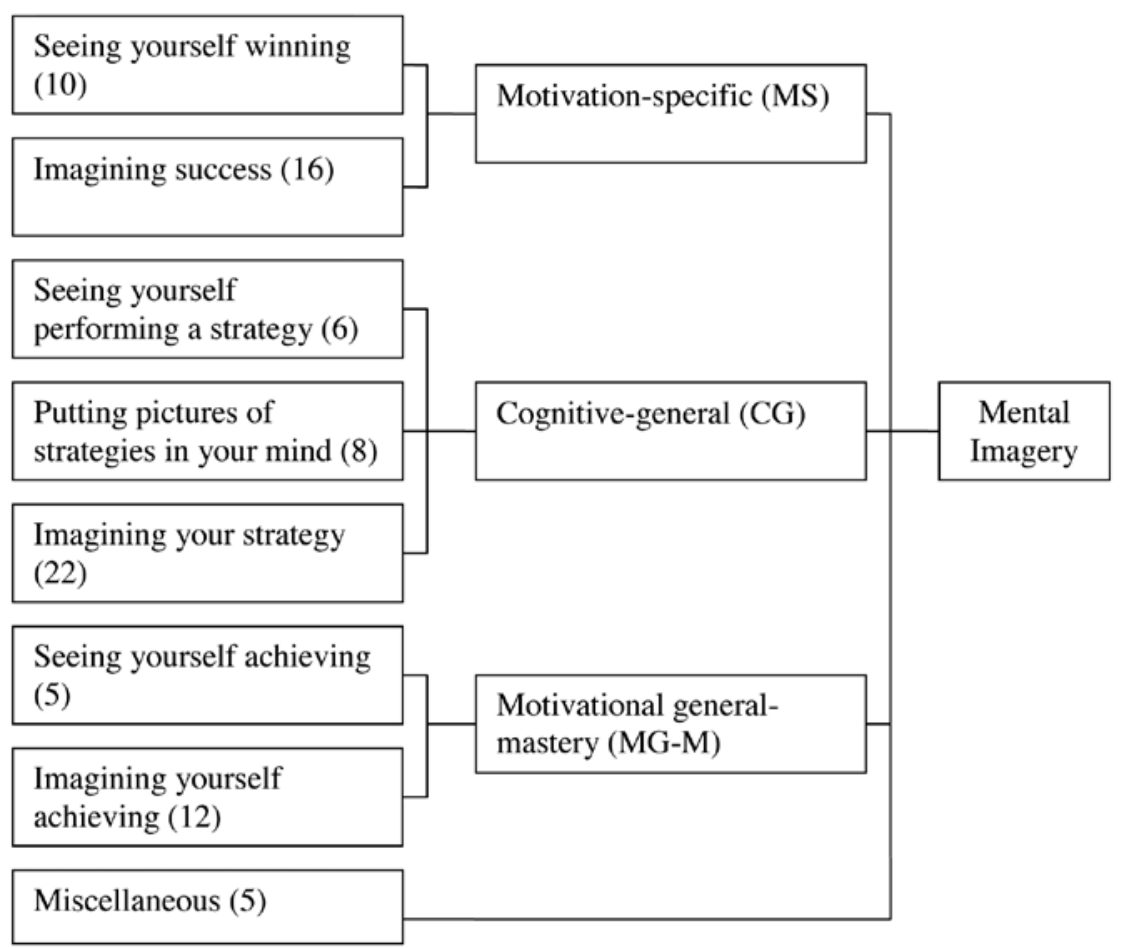

Figure 2 - Hierarchical structure of general dimension: mental imagery.

mastery. This category included responses such as "you see yourself doing something good before you have even done it," "when you visualize getting it right or doing it," and "imagining yourself doing well." Thirty-one percent of the participants identified mental imagery as cognitive-general. For instance, mental imagery was described as "you are seeing in your head what you want to happen," "picturing what you are going to do," and "imagining what you are going to do before actually trying to do it." Within each of these categories, MS, CG, and MG-M participants reported using their visual senses only to create or recreate an experience in their minds. These responses show that mental imagery processes among this sample are not, at least initially, identified as multisensory experiences. For example, participants did not report "hearing" or "feeling" stimuli or sensations. Further probing may have uncovered this experience. Miscellaneous items accounted for $3 \%$ of the recorded responses. Motivation general-arousal (e.g., imagining the arousal and anxiety associated with performance) or cognitive-specific (e.g., mental rehearsal of skills) imagery did not emerge from the responses of these athletes. Although researchers have demonstrated that MG-A imagery was related to decreased anxiety (Vadocz, Hall, \& Moritz, 1997) and that CS imagery use is positively related to performance improvements (Driskell, Copper, \& Moran, 1994), these athletes did 
not associate mental imagery with these functions. Given the age of these athletes and the nature of abstract concepts such as mental imagery, it would be difficult to expect them to report all five functions of mental imagery. Ninety-five percent of all respondents indicated that they understood the term mental imagery using Vealey and Greenleaf's (2006) definition as a guide.

Self-Talk. Respondents generally reported that self-talk was a "strategy" to achieve one's goals or to "enhance one's confidence," and was "internal or external dialogue" (see Figure 3). Sixty-four participants' (54\%) completed responses were recorded. Nine percent of the total respondents reported that self-talk was "task instruction" used to perform in their sport. Examples include "to tell yourself what you want yourself to do" and "to talk yourself through what you've got to do." Twenty-five percent of total respondents indicated that self-talk was motivating verbal persuasion: "telling yourself you can do it," "talk positively to yourself to help yourself to do well," and "talking yourself into a frame of mind to win." Previously, researchers demonstrated that athletes use self-talk in an effort to improve confidence (Gould, Hodge, Peterson, \& Giannini, 1989) and motivation (Van Raalte, Brewer, Rivera, \& Petitpas, 1994). A qualitative analysis of self-talk by Hardy, Gammage, and Hall (2001) reported that self-talk serves cognitive (instructional) and motivational functions for the athletes, both of which can be further subdivided. First, cognitive function can be specific (e.g., skill learning) or general (e.g., strategy execution). The motivational function can be arousal (e.g., psyching oneself up), mastery (e.g., focus, confidence, mental preparation), or drive (e.g., increasing effort). The athletes in the present inquiry reported self-talk as a cognitive and motivational technique, corroborating the work of Hall et al. (1998) and Hardy, Hall, and Hardy (2005). Twelve percent of respondents described selftalk as an action: "talking to yourself." Although the current study did not assess why athletes use self-talk, the reports suggested that self-talk serves a mastery
$1^{\text {st }}$ order theme
$2^{\text {nd }}$ order theme
General Dimension

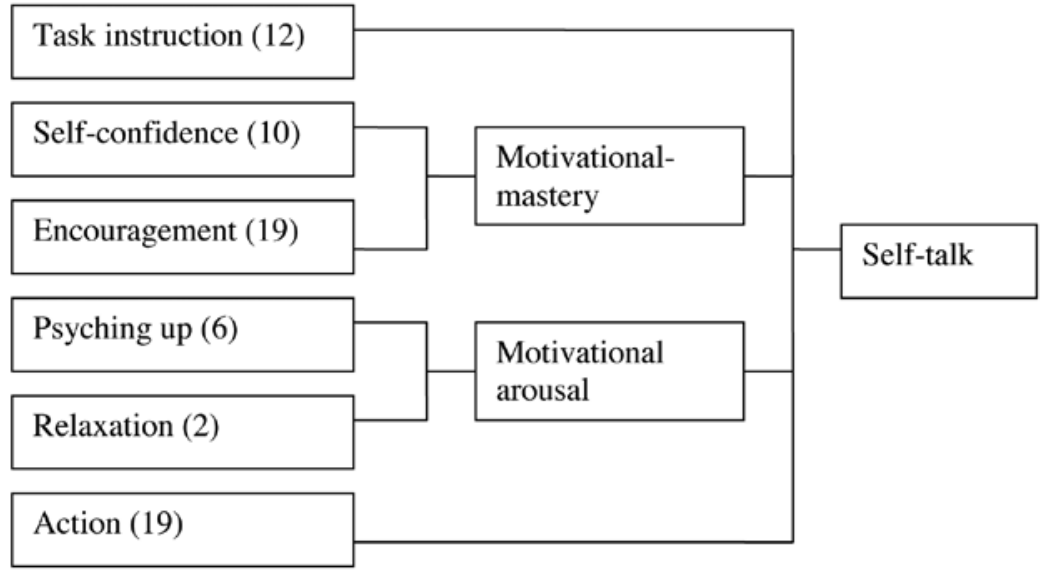

Figure 3 - Hierarchical structure of general dimension: self-talk. 
function, which corresponds with why athletes use mental imagery (Hardy et al., 2001). According to Hall et al. (1998), athletes use mental imagery more for mastery purposes than any other purpose, logically suggesting that athletes should be encouraged to use mastery self-talk and mental imagery together (Hardy et al., 2001). By definition, self-talk serves instructional and motivational functions, which $70 \%$ of the completed responses indicated, suggesting that self-talk was generally well understood by those respondents.

Relaxation. Similar to self-talk, participants broadly defined relaxation. Two second-order themes emerged, physical and mental relaxation, with many lower-order themes such as stress reduction, anger management, confidence, concentration, and success (see Figure 4). Seventy-six participants' (64\%) completed responses were recorded. Forty percent of the total sample indicated that relaxation was a technique for stress reduction. Examples include "when you are under pressure you can relax and calm down," "to calm your mind when you're nervous at a competition," and "to calm down by doing slow moves and sitting quietly." Anger management accounted for 3\% of the samples' responses: "keeping your cool and not losing your temper" and "relax and not get angry." Relaxation was also associated with mental relaxation factors, which accounted for $14 \%$ of the total responses. In particular, mental relaxation was associated with cognitions of success (3\%), confidence (6\%), and concentration $(5 \%)$. For example, respondents explained relaxation as "focus on winning," "being confident," and "being able to concentrate on what you are doing." Based on these responses, these young athletes view relaxation not only as physical but also mental relaxation. The direction of the association with confidence is not explained; therefore, theoretically one may be cognitively relaxed because one is confident. This understanding of relaxation by these young athletes does appear to fit generally with the description

$$
1^{\text {st }} \text { order themes } \quad 2^{\text {nd }} \text { order themes General Dimension }
$$

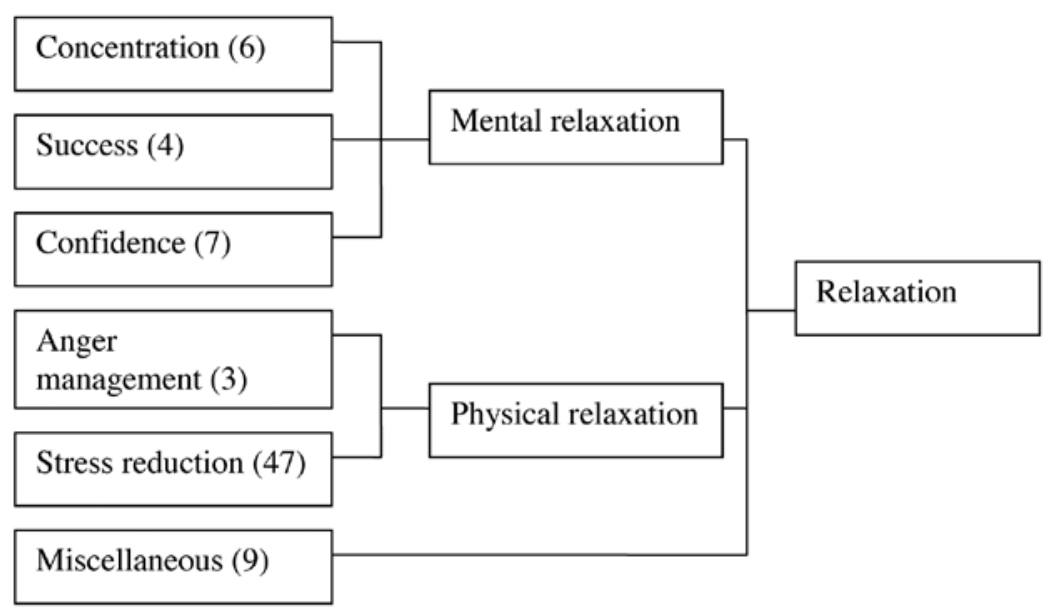

Figure 4 - Hierarchical structure of general dimension: relaxation. 
of relaxation. For instance, at a practical level, the ability to relax is an important aspect of achieving optimal performance in sport. Specifically, relaxation is useful to control anxiety to manageable proportions and being relaxed during performance is considered to be one characteristic of flow (Jackson, 1992).

\section{Discussion}

This study explored young athletes' implicit knowledge of four basic psychological skills: goal setting, mental imagery, self-talk, and relaxation. Results indicated that young athletes have some understanding of these skills. In particular, athletes in the specializing years (aged 13-16 years) of sport participation appear to have a superior understanding of these basic psychological skills compared with athletes in the sampling years (aged 7-12 years), highlighting a possible developmental difference in understanding such abstract concepts between these two age groups (Foster \& Weigand, 2008; Piaget, 1963, 1970). It also suggests that children who have not reached the formal operational stage of cognitive development (approximately 12 years of age; Piaget, 1963, 1970) may need additional education and guidance to understand these skills. This sample of participants, however, was limited to one geographical area in England, and factors other than age (e.g., education) could help explain these findings. This sample of young athletes demonstrated greatest knowledge and understanding when explaining goal setting and mental imagery, whereas relaxation and self-talk were less well explained. In addition, only the visual sense of mental imagery emerged in their understanding of mental imagery. Attending to Stallard's (2005) advice, suitable education is necessary to help children understand psychological skills and assist them in integrating these skills into practice and competition. Sinclair and Sinclair (1994) created a model of mental management that embedded psychological skills training in the process of learning physical skills. Mental skills were taught, learned, and remembered more easily when developed along with physical skills.

\section{Limitations and Future Directions}

To prevent unjustified extrapolation of the results of this study, several limitations warrant discussion. The sample used in the current study was limited to young athletes in the sampling and specializing years of sport participation. In addition, the sample came from only one primary and two secondary schools, and the schools were from the same region in England. Further, the relationship between the findings and gender and ethnicity was not evaluated. These issues may limit the generalizability of these results. Future studies should include athletes from the investment or recreation years (aged 17+ years) to develop a comprehensive appreciation of all young athletes' understanding and use of psychological skills. In addition, replicating the current study with elite and nonelite young athletes would provide an interesting comparison. The lack of depth associated with this survey research (i.e., no chance to further probe athlete insights on particular psychological skills) prevents us from reaching definitive conclusions about young athletes' implicit knowledge of psychological skills. This research, however, does begin to deepen the understanding of the developmental differences associated with psychological skill understanding and use among youth sport participants. Previously, Goudas and 
Biddle (1993) indicated that the use of open-ended questions with this age group leads to "surface level" answers; therefore, further probing through appropriate questions or the use of focus groups is sensible.

Further studies are necessary to establish ages at which psychological skills can be best taught and integrated into practice and competition for young athletes. Sport psychologists should also determine how best to adapt cognitive behavioral interventions so that they are most effective with young athletes. In addition, it would be helpful to assess how young athletes learn to integrate psychological skills into practice and competition and how young athletes who learn psychological skills actually adhere to psychological skills practice. By assessing these issues, we can begin to help young athletes cope with and enjoy the challenges in sport.

\section{Conclusion}

Since knowledge of young athletes' implicit understanding of psychological skills used in sport is limited at this time, the current study explored young athletes' implicit knowledge of psychological skills in sport and highlighted the possible developmental differences that exist between young athletes in the sampling and specializing years of sport participation. Introducing young athletes to these concepts and educating them appropriately can help them to learn and integrate these skills into their sporting lives (Sinclair \& Sinclair, 1994; Stallard, 2002, 2005). Within the lifespan model of careers transitions, young athletes in school could benefit from psychological skills taught in physical education classes that would benefit sport involvement outside of the school setting. If education and training in psychological skills are appropriately adapted for young athletes, perhaps these athletes could benefit from the use of psychological skills to commit to sport and enhance sport performance and learn to transfer these skills to other life domains.

\section{References}

Andersen, M.B. (Ed.). (2000). Doing sport psychology. Champaign, IL: Human Kinetics. Andersen, M.B. (2009). Sport psychology in practice. In B. Brewer (Ed.), The Olympic handbook of sports medicine and science: Sport psychology (pp. 121-132). Oxford: Wiley-Blackwell.

Anderson, A.G., Miles, A., Mahoney, C., \& Robinson, P. (2002). Evaluating the effectiveness of applied sport psychology practice: Making the case for a case study approach. The Sport Psychologist, 16, 432-453.

Benson, P.L. (1997). All kids are our kids: What communities must do to raise caring and responsible children and adolescents. San Francisco: Jossey-Bass.

Biddle, S., Markland, D., Gilbourne, D., Chatzisarantis, N., \& Sparkes, A.C. (2001). Research methods in sport and exercise psychology: Quantitative and qualitative issues. Journal of Sports Sciences, 19, 777-809.

Billings, A.G., \& Moos, R.H. (1984). Coping, stress, and social resources among adults with unipolar depression. Journal of Personality and Social Psychology, 46, 877-891.

Bruner, M.W., Erickson, K., McFadden, K., \& Côté, J. (2009). Tracing the origins of athlete development models in sport: A citation path analysis. International Review of Sport and Exercise Psychology, 2, 23-37.

Corlett, J. (1996). Sophistry, Socrates and sport psychology. The Sport Psychologist, 10, 84-94. 
Côté, J., Baker, J., \& Abernethy, B. (2007). Practice and play in the development of sport expertise. In R. Eklund \& G. Tennenbaum (Eds.), Handbook of sport psychology (3rd ed., pp. 184-202). Hoboken, NJ: Wiley.

Davis, N.W., \& Meyer, B.B. (2009). Qualitative data analysis: A procedural comparison. Journal of Applied Sport Psychology, 21, 116-124.

Driskell, J.E., Copper, C., \& Moran, A. (1994). Does mental practice enhance performance? The Journal of Applied Psychology, 79, 481-492.

Eccles, D.W., Walsh, S.E., \& Ingledew, D.K. (2002). A grounded theory of expert cognition in orienteering. Journal of Sport \& Exercise Psychology, 24, 68-88.

Erikson, E.H. (1963). Childhood and society. New York: Stonton.

Foster, D.J., \& Weigand, D.A. (2008). The role of cognitive and metacognitive development in mental skills training. Sport and Exercise Psychology Review, 4, 21-29.

Fraser-Thomas, J., Côté, J., \& Deakin, J. (2005). Youth sport programs: An avenue to foster positive youth development. Physical Education and Sport Pedagogy, 10, 19-40.

Goudas, M., \& Biddle, S. (1993). Pupil perceptions of enjoyment in physical education. Physical Education Review, 16, 145-150.

Gould, D., Hodge, K., Peterson, K., \& Giannini, J. (1989). An exploratory examination of strategies used by elite coaches to enhance self-efficacy in athletes. Journal of Sport \& Exercise Psychology, 11, 128-140.

Glaser, B., \& Strauss, A. (1967). The discovery of grounded theory: Strategies for qualitative research. New York: Aldine.

Hall, C.R., Mack, D.E., Paivio, A., \& Hausenblas, H.A. (1998). Imagery use by athletes: Development of the Sport Imagery Questionnaire. International Journal of Sport Psychology, 23, 1-17.

Hardy, J., Gammage, K., \& Hall, C. (2001). A descriptive study of athlete self-talk. The Sport Psychologist, 15, 306-318.

Hardy, J., Hall, C.R., \& Hardy, L. (2005). Quantifying athlete self-talk. Journal of Sports Sciences, 23, 905-917.

Hardy, L., Jones, G., \& Gould, D. (1996). Understanding psychological preparation for sport: Theory and practice of elite performers. Chichester: Wiley.

Harwood, C. (2008). Developmental consulting in a professional football academy: The 5Cs coaching efficacy program. The Sport Psychologist, 22, 109-133.

Harwood, C.G., Cumming, J., \& Fletcher, D. (2004). Motivational profiles and psychological skill use within elite youth sport. Journal of Applied Sport Psychology, 16, 318-332.

Harwood, C.G., Cumming, J., \& Hall, C. (2003). Imagery use in elite youth sport participants: Reinforcing the applied significance of achievement goal theory. Research Quarterly for Exercise and Sport, 3, 292-300.

Harwood, C., \& Knight, C. (2009). Stress in youth sport: A developmental investigation of tennis parents. Psychology of Sport and Exercise, 10, 447-456.

Havighurst, R.J. (1973). History of developmental psychology: Socialization and personality development through the lifespan. In P.B. Baltes \& K.W. Schaie (Eds.), Lifespan developmental psychology: Personality and socialization (pp. 3-24). New York: Academic Press.

Horn,T.S., \& Weiss, M.R. (1991). A developmental analysis of children's self-ability judgments in the physical domain. Pediatric Exercise Science, 3, 310-326.

Jackson, S.A. (1992). Athletes in flow: A qualitative investigation of flow states in elite figure skaters. Journal of Applied Sport Psychology, 4, 161-180.

Kremer, J., \& Moran, A.P. (2008). Pure sport: Practical sport psychology. London: Routledge.

Lane, A.M., Harwood, C., Terry, P.C., \& Karageorghis, C.I. (2004). Confirmatory factor analysis of the Test of Performance Strategies (TOPS) among adolescent athletes. Journal of Sports Sciences, 22, 803-812. 
Lazarus, R., \& Folkman, S. (1984). Stress, appraisal, and coping. New York: Springer.

McCarthy, P.J., Jones, M.V., \& Clark-Carter, D. (2008). Understanding enjoyment in youth sport: A developmental perspective. Psychology of Sport and Exercise, 9, 142-156.

McCarthy, P.J., \& Jones, M.V. (2007). A qualitative study of sport enjoyment in the sampling years. The Sport Psychologist, 21, 400-416.

Marshall, C., \& Rossman, G.B. (1995). Designing qualitative research (2nd ed.). Thousand Oaks, CA: Sage.

Martin, K.A., Moritz, S.E., \& Hall, C. (1999). Imagery use in sport: A literature review and applied model. The Sport Psychologist, 13, 245-268.

Miles, M.B., \& Huberman, A.M. (1994). Qualitative data analysis (2nd ed.). London: Sage.

Moran, A.P. (1996). The psychology of concentration in sport performers: A cognitive analysis. Hove, East Sussex: Psychology Press/Taylor \& Francis.

Murphy, S., \& Tammen, V. (1998). In search of psychological skills. In J. Duda (Ed.), Advances in sport and exercise psychology measurement (pp. 195-209). Morgantown, WV: Fitness Information Technology.

Partington, J., \& Orlick, T. (1987). The sport psychology consultant evaluation form. The Sport Psychologist, 1, 309-317.

Patton, M. (2002). Qualitative research and evaluation methods. Thousand Oaks, CA: Sage.

Piaget, J. (1970). Piaget's theory. In P. Mussen (Ed.), Manual of child psychology (pp. 103-128). London: Wiley.

Piaget, J. (1963). The origins of intelligence in children. New York: Norton.

Pidgeon, N., \& Henwood, K. (1997). Using grounded theory in psychological research. In N. Hayes (Ed.), Doing qualitative analysis in psychology (pp. 245-274). Hove, England: Psychology Press.

Scanlan, T.K., Babkes, M.L., \& Scanlan, L.A. (2005). Participation in sport: A developmental glimpse at emotion. In J.L. Mahoney, R.W. Larson, \& J.S. Eccles (Eds.), Organized activities as contexts of development: Extracurricular activities, after-school and community programs (pp. 275-309). Mahwah, NJ: Lawrence Erlbaum Associates.

Sinclair, G.D., \& Sinclair, D.A. (1994). Developing reflective performers by integrating mental management skills with the learning process. The Sport Psychologist, 8, 13-27.

Smith, R. E. (1989). Applied sport psychology in an age of accountability. Journal of Applied Sport Psychology, 1, 166-180.

Stallard, P. (2005). A clinician's guide to Think Good-Feel Good: Using CBT with children and young people. Chichester: Wiley.

Stallard, P. (2002). Think Good - Feel Good: A cognitive behaviour therapy workbook for children and young people. Chichester: Wiley.

Thomas, P. (1990). An overview of the performance enhancement process in applied psychology. Unpublished manuscript, United States Olympic Training Center at Colorado Springs.

Vadocz, E.A., Hall, C.R., \& Moritz, S.E. (1997). The relationship between competitive anxiety and imagery use. Journal of Applied Sport Psychology, 9, 241-253.

Van Raalte, J.L., Brewer, B.W., Rivera, P.M., \& Petitpas, A.J. (1994). The relationship between observable self-talk and competitive junior tennis players' match performances. Journal of Sport \& Exercise Psychology, 16, 400-415.

Vealey, R.S. (1988). Future directions in psychological skills training. The Sport Psychologist, 2, 318-336.

Vealey, R.S., \& Greenleaf, C.A. (2006). Seeing is believing: Understanding and using imagery in sport. In J.M. Williams (Ed.), Applied sport psychology: Personal growth to peak performance (5th ed., pp. 285-305). Mountain View, CA: Mayfield Publishing.

Weinberg, R.S. (2002). Goal setting in sport and exercise: Research to practice. In J. Van Raalte \& B.W. Brewer (Eds.), Exploring sport and exercise psychology (2nd ed., pp. 25-48). Washington, DC: American Psychological Association. 
Weiss, M.R., \& Bredemeier, B.J. (1983). Developmental sport psychology: A theoretical perspective for studying children in sport. Journal of Sport Psychology, 5, 216-230.

Weiss, W.M., \& Weiss, M.R. (2006). A longitudinal analysis of commitment among competitive female gymnasts. Psychology of Sport and Exercise, 7, 309-323.

Wiese-Bjornstal, D.M., LaVoi, N.M., \& Omli, J. (2009). Child and adolescent development and sport participation. In B. Brewer (Ed.), The Olympic handbook of sports medicine and science: Sport psychology (pp. 97-112). Oxford: Wiley-Blackwell.

Wylleman, P., Alfermann, D., \& Lavallee, D. (2004). Career transitions in sport: European perspectives. Psychology of Sport and Exercise, 5, 7-20. 